\title{
$\bigwedge_{\text {GEEGRALIE }}^{\operatorname{TTE}}$
}

\section{Cotidiano e redes de sociabilidades no Assentamento São Bento, Heitoraí/Go (1996-2019)}

\author{
Daily life and networks of sociability in São Bento \\ Settlement, Heitoraí/Go (1996-2019)
Cotidiano y redes de sociabilidades en el Asentamiento São Bento, Heitoraí/Go (1996-2019)

\author{
Jean Carlos Ribeiro de Lima \\ Universidade Estadual de Goiás \\ jean_ribeiro_lima@hotmail.com
}

\begin{abstract}
Resumo
As redes de sociabilidades constituem-se a partir de relações subjetivas entre diferentes sujeitos e em múltiplos espaços sociais. Tais relações, que primam pela subjetividade, apresentam-se sob inúmeras formas, tais como, por meio do apoio mútuo, da cooperação, do associativismo e da reciprocidade. Dessa forma, objetivamos com este estudo analisar as redes de sociabilidades existentes no cotidiano dos assentados do São Bento, por meio das trajetórias de vida, de suas experiências tanto individuais, quanto coletivas e as vivências adquiridas. A discussão está fundamentada em revisão bibliográfica acerca da temática dos assentamentos rurais e das redes de sociabilidades, bem como em trabalho de campo onde foi possível o recolhimento de dados quantitativos e qualitativos, por meio da aplicação de questionários e realização de entrevistas nas parcelas e residências dos assentados. A partir da análise dos dados foi possível identificar que no espaço social do Assentamento São Bento em Heitoraí/GO, as redes de sociabilidades contribuem para a manutenção e a reprodução das relações sociais entre os assentados.
\end{abstract}

Palavras-chave: Assentamento. Trajetórias. Sociabilidades.

\begin{abstract}
Networks of sociabilities are constituted from subjective relationships between different subjects and in multiple social spaces. Such relationships, which excel for the subjectivity, present themselves in numerous forms, such as, through the mutual support, the cooperation, the associativism and the reciprocity. Thus, we aim with this study to analyze the existing networks of sociabilities in the settlers' daily life of São Bento, through their life trajectories, their individual and collective experiences and the experiences acquired. The discussion is based on a bibliographical review about the theme of rural settlements and networks of sociabilities, as well as on field work where it was possible to collect quantitative and qualitative data, by means of applying
\end{abstract}


questionnaires and conducting interviews in the settlers' plots and residences. From the data analysis it was possible to identify that in the social space of São Bento Settlement in Heitoraí/GO, the networks of sociabilities contribute to the maintenance and reproduction of the social relations among the settlers.

Keywords: Settlement. Trajectories. Sociabilities.

\begin{abstract}
Resumen
Las redes de sociabilidad se constituyen a partir de relaciones subjetivas entre diferentes sujetos y en múltiples espacios sociales. Estas relaciones, que se basan en la subjetividad, se presentan en numerosas formas, como el apoyo mutuo, la cooperación, el asociacionismo y la reciprocidad. Así pues, con este estudio se pretende analizar las redes de sociabilidades que existen en la vida cotidiana de los colonos de São Bento, a través de sus trayectorias de vida, sus experiencias individuales y colectivas y las experiencias adquiridas. El debate se basa en un examen bibliográfico sobre el tema de los asentamientos rurales y las redes de sociabilidad, así como en la labor sobre el terreno, en la que fue posible reunir datos cuantitativos y cualitativos mediante la aplicación de cuestionarios y entrevistas en las parcelas y residencias de los asentamientos. A partir del análisis de los datos fue posible identificar que en el espacio social del asentamiento de São Bento en Heitoraí/GO, las redes de sociabilidad contribuyen al mantenimiento y reproducción de las relaciones sociales entre los colonos.
\end{abstract}

Palabras Clave: Asentamiento. Trayectorias. Sociabilidades.

\title{
Introdução
}

O filósofo francês Henri Lefebvre (1991) elaborou um método de investigação científica que denominou de "regressivo-progressivo". Este método, segundo Lefebvre, consistiria na compreensão da realidade social pela via da observação, da descrição e da comparação. Ao pesquisador, caberia a difícil tarefa de observar a dinâmica das relações sociais, descrevê-las em suas particularidades e, por fim, estabelecer uma abordagem comparativa fundada em múltiplas possibilidades. Ao valorizar a interdisciplinaridade como um dos pilares de seu método, Lefebvre (1991) entende que os fenômenos sociais são caracterizados por diversas variáveis (social, econômico, político, cultural, tradicional, simbólico etc) e que, portanto, cabe às diversas áreas do conhecimento, como a História, a Sociologia, a Geografia, a Antropologia, e outras, a responsabilidade de se ocuparem dessa realidade.

Na contramão do determinismo marxista, a leitura e a compreensão da realidade social para Lefebvre (2016) consistem em um tripé: o vivido, o percebido e o concebido. Nessa tríade está a essência da realidade social e onde flui o genuíno pulsar da vida cotidiana. Cotidiano, aliás, que escapa ao econômico, ao capital, ao Estado, à luta de classes, porque também é um cotidiano da produção da arte, do desejo, da fruição, do valor de uso. Essas são as possibilidades que o artigo procura evidenciar: investigar (observação) as trajetórias de vida dos sujeitos (assentados) e interpretá-las em suas especificidades; narrar e apresentar (descrição) a dinâmica social resultado de conflitos e experiências acumuladas de sujeitos que passam a viver em um mesmo espaço social (acampamento/assentamento); perscrutar (comparação) os eventos e a fluidez das relações e suas possibilidades introspectivas, suas nuances no cotidiano. 
Convém assinalar que o Assentamento São Bento constitui parte importante, e dela também é resultado, da dinâmica socioeconômica e histórica de Heitoraí/GO, pequeno município goiano (Figura 01) com população de 3.571 habitantes (IBGE, 2010) e uma economia bastante voltada à produção agropecuária. A produção agrícola é o principal mote da economia do município, com destaque para a produção de banana, que registrou 5.200 toneladas em 2018, melancia (3.100 toneladas), milho (3.008 toneladas) e arroz (207 toneladas). Também se destacam a produção de cana-de-açúcar, que registrou 68.000 toneladas em 2016 e mandioca, com 620 toneladas naquele mesmo ano (GOIÁS, 2020). O rebanho bovino somou em 2018, 31.200 cabeças e 3.250 vacas ordenhadas (GOIÁS, 2020). No que se refere à estrutura agrária do município, prevalece a incidência de pequenos e médios estabelecimentos agrícolas, incluindo os lotes e parcelas dos assentamentos (IBGE, 2010-2015; SEGPLAN, 2010).

A realidade social, a dinâmica produtiva e a configuração territorial do município sofreram alterações pontuais a partir de meados da década de 1996, não apenas do São Bento, mas também de outros assentamentos1. Essas transformações reconfiguraram não apenas espaços produtivos, econômicos e geográficos, mas também recondicionou relações sociais, introduzindo novas vivências e perpetuando antigas experiências.

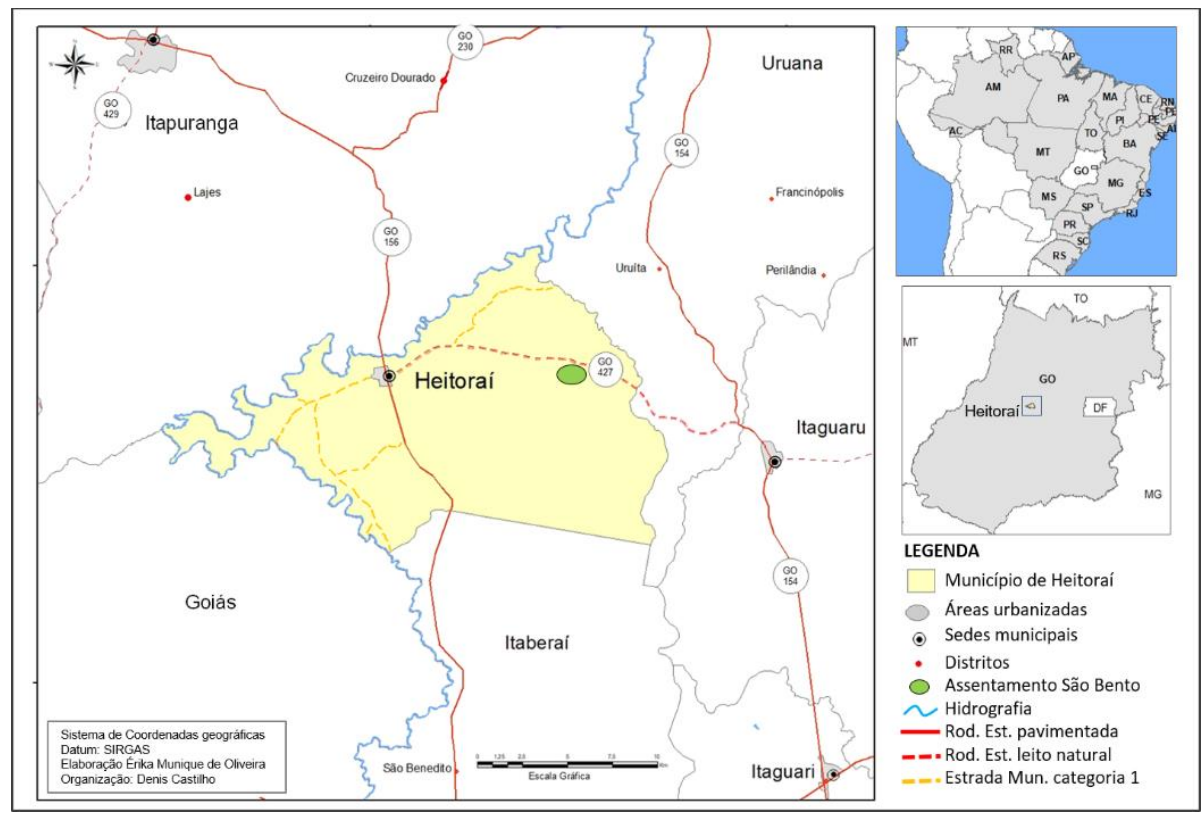

Figura 01: Localização do município de Heitoraí (GO).

Fonte: Castilho (2007).

\footnotetext{
${ }^{1}$ Além do assentamento São Bento, existem outros quatro assentamentos em Heitoraí, aos quais, assentamento Lagoa Grande, Bom Jesus, Brumado e Margarida Alves.
} 
$\mathrm{Na}$ esteira da necessidade de aprender a dinâmica dos processos sociais que envolvem os assentados e a formação do espaço social do assentamento São Bento, adotamos, como procedimento investigativo e metodológico, a realização de entrevistas, aplicação de questionários e conversas informais. Todos estes procedimentos foram realizados durante o ano de 2017, buscando, primeiramente, estabelecer e criar um vínculo entre pesquisador e sujeitos da pesquisa, por isso a importância dos primeiros contatos, fossem nas ruas, mercados ou farmácias de Heitoraí, ou mesmo em visitas prévias nos lotes e parcelas dos assentados.

O grande volume de informações e dados foram colhidos mediante as entrevistas realizadas nas respectivas residências e parcelas dos assentados. Estando no ambiente do assentamento, na gleba e na residência dos assentados, pudemos perceber, vivenciar e conceber uma variedade de histórias, trajetórias e experiências de vida, tanto coletivas, quanto individuais. Tivemos, também, acesso a documentos e fontes de cunho pessoal e coletivo, como fotos, cartas, atas de reuniões e textos jurídicos. Além disso, realizou-se trabalho de campo e de pesquisa nos arquivos do Instituto Nacional de Colonização e Reforma Agrária (INCRA), no município de Goiânia, no final de 2016. Esse trabalho foi importante para obtermos informações a respeito de questões técnicas e históricas do assentamento e dos próprios assentados ${ }^{2}$.

Nesse sentido, o espaço social do Assentamento São Bento apresenta-se repleto de singularidades cotidianas, que emergem nos interstícios da vida, do trabalho, da produção, da comercialização, da burocratização. Esse cotidiano engessado, capturado pelo binômio capital-estado é transpassado por mecanismos de reprodução social que vão além da objetividade. Chega-se à subjetividade das relações sociais, nas mais variadas formas: mutirões, trocas de dia, cooperação e associativismo. No interior do assentamento, tais formas se tornam meios de sobrevivência e de vivências partilhadas, que não sem razão, também são fruto de conflitos.

\section{Espaços vividos: histórias, trajetórias e experiências dos assentados de São Bento}

De muitas formas, as trajetórias de vida são, em maior ou menor grau, determinadas por aspectos sociais, políticos, econômicos, mas também culturais, tradicionais, místicos, naturais, geográficos etc. Conforme Gonçalves e Lisboa (1996), toda trajetória de vida pode ser considerada uma instituição social, um sistema de regras (que não é fixo) mas que rege e conduz as relações do indivíduo ou do grupo. Com efeito, a dimensão ampliada do termo incorpora a diversidade de funções que o sujeito ou o grupo social ocupam sucessivamente no tempo e no espaço. No assentamento São Bento, a construção dos laços de sociabilidades foi moldada a partir das trajetórias de vida dos sujeitos, neste caso de trabalhadores rurais, homens e mulheres em busca de um pedaço de.

\footnotetext{
${ }^{2} \mathrm{Na}$ mencionada pesquisa realizada no INCRA, tivemos acesso ao Projeto de Criação do Assentamento São Bento, onde todas as informações referentes a datas, decretos, tamanho da propriedade, quantidade de famílias acampadas, quantidade e tamanho de lotes e número de famílias assentadas foram extraídas.
} 
Esse movimento de composição das sociabilidades entre os assentados ocorreu de duas maneiras. Em primeiro lugar, por meio da experiência de vida de cada homem, mulher e criança que, a partir do ano 1996 , montaram barracos de lona preta às margens da GO-427, e ali edificaram um acampamento, denominado Córrego Seco ${ }^{3}$. À época, pouco mais de trezentas famílias de trabalhadores e trabalhadoras rurais estiveram participando da ocupação das margens da mencionada rodovia, que liga os municípios de Heitoraí e Itaguaru.

Em razão do contexto histórico abarcar a década de 1990 - período de maior efervescência da política de assentamentos rurais no Brasil -, as notícias que eram vinculadas a respeito de propriedades rurais com problemas judiciais, de dívidas e que não cumpriam os requisitos necessários, como a função social da terra, os trabalhadores migravam de uma região para a outra, na expectativa de poder conseguir um pedaço de terra. Essa frenética migração, fez com que, já no final do ano de 1997 e início do ano de 1998, o número inicialmente de trezentas famílias caísse vertiginosamente para quarenta. Por fim, após a consolidação do assentamento, foram de fato assentadas, trinta famílias.

A iniciativa do acampamento deveu-se ao trabalho de mediação da Comissão Pastoral da Terra (CPT/Cidade de Goiás), Igreja Católica e Diocese do município da Cidade de Goiás, o Sindicato dos Trabalhadores Rurais de Itapuranga, e a própria organização dos trabalhadores rurais da região. Em segundo, a experiência política acumulada a partir da luta pela terra no acampamento e, posteriormente, na criação do assentamento, foram fatores determinantes na configuração das relações e vínculos entre os assentados.

No tocante às trajetórias de vida, verificou-se que a maioria dos assentados que participaram da pesquisa já possuíam experiência com o trabalho no campo no período anterior ao acampamento/assentamento. Constatou-se também que boa parte dos assentados vieram de municípios vizinhos, como Itapuranga, Uruana, Cidade de Goiás e Inhumas. Esse dado corrobora a tese de que o trabalho de mediação e politização realizado por meio das entidades eclesiásticas e sindical (CPT/GO, STR/Itapuranga e Diocese/GO) foram determinantes, na medida em que informava, conscientizava e apoiava os trabalhadores na luta pela terra.

na época meu pai veio de Minas Gerais...aí nós ficamos um pouco em Goiás (Cidade de Goiás), nós fomos criados lá, na fazenda do Zé Machado, que até hoje é conhecido. Aí criou os filhos tudo, né; foram dez irmãos...aí ficamos um tempo lá; aí nós começamos a estudar [...] na verdade, eu sempre gostei de mexer com a roça, de mexer no campo, do verde, da natureza. E aí eu trabalhei em Goiás um tempo, e eu estudava, vendia mexerica, laranja, nos

${ }^{3}$ Córrego que se localizava na GO-427 e que já era assim denominado na região antes da chegada dos trabalhadores. 
intervalos...nessa época nós tínhamos um bar-restaurante também, isso na cidade (ASSENTADO AX-4, grifo nosso) ${ }^{4}$.

O depoimento dos assentados reforça a afirmação anterior: a experiência com o trabalho no campo. Na maioria dos casos, a condição de trabalho dos assentados estava subordinada ao que o sociólogo Octavio Ianni (1984) defini como "assalariamento rural". Isto é, um processo pelo qual o capital se apropria da força de trabalho no campo e a transforma em mais-valia. Na situação a que se encontravam, muitos dos assentados relataram que não tinham opções, pois “[...] ou trabalhava para alguém, ou passava fome” (ASSENTADO, AX-1).

A condição de itinerantes é uma característica definidora do campesinato brasileiro, como defende Martins (1983). Para este autor, o campesinato é aquele que não está de fora, mas também não está de dentro; que precisa estar quase sempre alternando de um lugar para o outro porque não possui a terra, meio de produção que necessita para trabalhar e sobreviver. Não houve sequer, como é possível observar, um relato que não enfatizasse essa itinerância dos assentados de São Bento.

Na realidade dura e difícil da alternância de espaços e sonhos, as trajetórias dos assentados do São Bento revelam que a possibilidade de acesso à terra poderia dar um alento "[...] nessa vida de andanças sem rumo e incertezas" (ASSENTADO AX - 8). As narrativas descrevem, em uníssono, que a notícia de que a então Fazenda São Bento do Taquaral, localizado no município de Heitoraí/GO estava para ser embargada e confiscada pelo INCRA. A notícia corria solta e constituía o que Martins (2003, p. 29) denomina ser uma "rede de boatos no mundo rural, base de circulação de informações sobre possíveis ocupações de terra, mobilizações e acampamentos". Conforme o relato do assentado AX9, essa rede de boatos e notícias foi determinante para a ocupação e formação do acampamento Córrego Seco:

rapaz, eu vou dizer pra você que eu vim pra cá porque um cunhado meu disse que era pra eu ficar velhaco que ia sair umas terras pra essas banda aqui, né...porque eu já mexia com roça a vida toda, né (assentado AX-9).

Quando a notícia passou de uma informação imprecisa para algo concreto, não houve, por parte dos assentados, qualquer hesitação em participar da ocupação da GO-427 e, por conseguinte, construir ali um acampamento. Quando os assentados relatam suas trajetórias de vida e apresentam suas dificuldades ao longo da experiência como assalariados rurais, sejam nas múltiplas e complexas relações sociais e de trabalho (agregados, arrendatários, diarista, boia-fria, meeiro, etc.), a perspectiva do

\footnotetext{
${ }^{4}$ A autoria dos depoimentos citados no corpo do texto estará descrita em pseudônimos. Está é uma determinação normativa contida na resolução 466/2012 do Conselho Nacional de Ética em Pesquisa (CONEP), que determina o direito legal de anonimato dos indivíduos que participam de qualquer pesquisa científica que envolva seres humanos. Vale ressaltar ainda que a pesquisa em tela seguiu todas as normas estipuladas pelo Conselho de Ética em Pesquisa (CEP) da Pontifícia Universidade Católica de Goiás (PUC/GO) e teve parecer aprovado em março de 2017.
} 
acampamento/assentamento aparece como utopia e ao mesmo tempo realidade de acesso à terra que trará, em consequência, dignidade e reconhecimento.

A luta pela terra, desde o antes, durante e depois do acampamento, estabeleceu determinado espaço no qual as vivências dos assentados aglutinaram-se em torno de objetivos comuns. No acampamento, as experiências puderam ser compartilhadas no sentido de construir vínculos e relações sociais com base na reciprocidade, mutualidade e cooperação no trabalho e na convivência cotidiana. Na unidade rural, as trajetórias de vida daqueles sujeitos revelam os dramas, as tragédias e os momentos de dificuldades enfrentados até conseguirem a terra e a partir dela dignidade para trabalhar e viver.

\section{O Cotidiano como invenção das sociabilidades: as experiências acumuladas pelos assentados}

Na acepção de Henri Lefebvre (1991), o cotidiano está imergido em uma "sociedade burocrática de consumo dirigido", isto é, definido e determinado por relações de produção e de consumo na qual predomina o valor de troca. É um cotidiano marcado pela obsolescência, pelo descartável, pelo imediatismo. Desse modo, nossa sociedade comporta necessidades conhecidas que logo serão satisfeitas, satisfação que consiste na rápida realização de uma "nova" necessidade (consumo), o que Lefebvre denomina de "saturação".

Para Michel de Certeau (1998), o conceito de cotidiano tem como fundamento a "arte de fazer", ou seja, das realizações e atividades ordinárias que executamos no dia a dia. Trata-se, portanto, de um cotidiano ordinário: levantar-se, trabalhar, comer, ler, escrever, morar, cozinhar, etc. Nessa concepção, o cotidiano emerge a partir do improviso, da mediação dos saberes, das técnicas, das experiências.

Na perspectiva de Pierre Bourdieu (1983) o cotidiano é entendido a partir da noção de habitus. Neste ponto, o autor considera dois aspectos fundamentais: a fenomenologia e a objetividade. O habitus implica num conjunto de práticas e representações já estruturadas que regulam e orientam a ação dos agentes sociais. Significa que o habitus é produto das relações sociais objetivas, determinando e condicionando o agir no espaço social dos sujeitos

Há uma relação muito próxima entre as trajetórias de vida dos assentados antes do acampamento, suas relações a partir da convivência no acampamento e a experiência adquirida no assentamento. Para tanto, o convívio e a experiência adquirida no espaço do acampamento Córrego Seco foi crucial no conjunto das estratégias de resistência para alcançarem o objetivo que era o acesso à terra.

De acordo com Ferrante (1994) a condição de demandantes de terra faz com que se crie um "espaço de iguais". Significa que no período que marca a formação do acampamento, o que se adquire é um processo de vivência que é definido pelos conflitos, embates, acordos, alianças, compromissos, coletividades, associativismos e mutualidades. Nesse sentido, o "espaço de iguais" é fortalecido porque o objetivo é comum a todos que 
estão ali, naquele espaço geográfico e social. Esse objetivo comum é encarnado na disposição e no entusiasmo com que os acampados demonstram em lutar pelo acesso à terra, mesmo que suas trajetórias de vida sejam parcialmente ou completamente distintas.

A partir das declarações, percebe-se que no período inicial da luta pela terra, que compreende basicamente a formação do acampamento e sua estruturação, a união e a cooperação dos trabalhadores estão mais bem definidas e consolidadas. Quando o objetivo principal é alcançado, isto é, o acesso à terra por meio do assentamento, a tendência é que a mesma cooperação e a mesma união antes tão importante na luta pela terra, ir aos poucos se decompondo, em alguns casos, até mesmo se dissipar por completo. Conforme fica explícito na fala do assentado AX-15: "[...] a união é complicada. Na hora do vamos ver, na hora em que todo mundo quer a terra, a união é total. Agora quando consegue a terra, essa união acaba".

A comparação da união no acampamento e no assentamento também é evidenciada pelos assentados AX-10 e AX-6, respectivamente: "bem, a união nossa aqui não é muito boa não. Na época do acampamento era bem mais forte a união"; "na época do Acampamento era maior. Hoje não tem união. Hoje é cada um para si”.

$\mathrm{Na}$ fase em que estão acampados, os trabalhadores precisam lidar com certos estranhamentos por força do convívio social, neste caso, o próprio acampamento. Tratase de um processo de "ressocialização", uma vez que provenientes de distintas origens e trajetórias, as formas de socialização das decisões, opiniões, moradia, alimentação, transporte e divisão possuem momentos de tensão e conflitos. Martins (2008) observa que os trabalhadores acampados são oriundos, em sua maioria, de famílias muito conservadoras, com uma visão de mundo familística e religiosa, de características arredias e imperativas.

Nesse contexto, o cotidiano dos assentados de São Bento encontra-se permeado por sociabilidades que escapam à reprodução das relações de produção, ao valor de troca, à mera objetividade das relações sociais, como defende Lefebvre (2016). Nos interstícios da vida cotidiana, como acredita Certeau (1998), da massificação do consumo e dos valores objetivos, a vida pulsa por meio de relações que não se moldam simplesmente pelo aspecto econômico.

(Re)elaboram-se "artes de fazer", meios de convivência fundados nas pequenas tessituras do cotidiano: o levantar, o cozinhar, o trabalhar, o bordar, o fazer. Exasperamse representações e sistemas pré-estabelecidos de comportamentos, gestos, gostos, opiniões e ações. O habitus que circunscreve o cotidiano também é transpassado por relações que vão além da engessada vida material e objetiva. Na perspectiva de Bourdieu (1983), expressamos e somos a expressão daquilo que assimilamos durante nossa existência, seja ela ao absorver em toda sua amplitude de experiências e relações, aspectos objetivos e/ou subjetivos. 


\section{Cooperação e associativismo: uma dimensão das redes de sociabilidades}

A diversidade de formação e organização de um assentamento rural podem ser dimensionadas por inúmeros aspectos. Christoffoli (2012) observa que a cooperação e o associativismo tanto abarcam a dimensão objetiva (mercado, meios de produção, capacitação e qualificação da força de trabalho) quanto a dimensão subjetiva (vontade das pessoas, seus sonhos e projetos). O grau de desenvolvimento e sucesso de determinadas formas de cooperação/associativismo dependerá, segundo o autor, do equilíbrio e da gestão dessas duas dimensões (objetiva e subjetiva). Diante disso, a cooperação e o associativismo representam, de um lado, uma forma de organização do trabalho e da produção que diminui os custos e maximiza os resultados, e de outro, traduz-se em um instrumento de transformação social e cultural.

No âmbito dos assentamentos rurais e dos processos organizativos que os definem, a cooperação e o associativismo são instrumentos essenciais para a manutenção e reprodução desses espaços sociais. Ademais, o sentido de tais modelos organizativos balizados por relações subjetivas, em muitos casos, extrapola a mera relação objetiva e econômica, desenvolvendo-se pela via da "cooperação espontânea". Uma das principais características da cooperação espontânea é o meio pelo qual a própria comunidade cria certo padrão de assistência social próprio a produzir e trocar remédios caseiros, ao criar mecanismos para cuidar das crianças e dos idosos cujos familiares necessitam sair do assentamento para trabalhar ou por outros motivos (SCOPINHO, 2012, p. 147).

O associativismo se define, por sua vez, pela prática de associar-se a alguém ou a determinado grupo, sem, necessariamente, estabelecer relações meramente oportunistas e de interesses pessoais, sustentando-se a partir da construção de vínculos que podem ser temporários ou permanentes, na observância das necessidades cotidianas de cada indivíduo ou grupo. $\mathrm{O}$ associativismo, assim como a cooperação, escapa à mera formalidade e objetivação econômica, ao traduzir relações que se operam mediante circunstâncias históricas e sociais específicas (BERGAMASCO; NORDER, 1996).

Segundo Zimmermann (1994, p. 205), “o assentamento rural é estudado enquanto um espaço de relações sociais onde as características heterogêneas individuais, homogeneizadas no processo de luta pela terra, ressurgem em bases novas". Essas "bases novas" são as redes de sociabilidades que emergem no cotidiano da coletividade rural como forma diferenciada de organização social e produtiva, culminando em alternativas de reprodução social distinta da dimensão econômica. Bergamasco (1994, p. 234) assinala que a heterogeneidade dos processos de reprodução social, diretamente associada a uma realidade como a de um assentamento rural, deve ser analisada em múltiplas dimensões da vida cotidiana, inclusive no que toca "às estratégias coletivas que perpassam estratégias em nível do próprio grupo familiar que resultam em tentativas vivenciadas de construção de espaços de sociabilidades".

Por meio das falas e dos depoimentos dos assentados, a questão das sociabilidades criadas a partir da realidade vivenciada e partilhada pelo grupo ficou evidente. De certo modo, a individualização, decorrente do processo de sorteio dos lotes 
e consequente formação do assentamento, não eliminou por completo as relações sociais baseadas no auxílio mútuo e na cooperação subjetiva essenciais para a reprodução social e luta pela terra. Quando perguntados sobre a união do grupo no assentamento em comparação com o acampamento, as falas foram unânimes em demonstrar que, no primeiro, o aspecto da união era mais nítido do que no segundo. Contudo, no mesmo instante em que narravam a dificuldade de manter a união de quando acampados, acrescentavam que quando um companheiro necessitasse e/ou solicitasse, estariam prontos para ajudar e auxiliar no que fosse preciso.

Em depoimento, o assentado AX-15 afirma que "dentro do assentamento nós ainda somos muito unidos, ainda fazemos uma ajuda com o companheiro que precisa de uma". O assentado AX-7 relata: "olha, o meu esposo planta arroz todo ano. No dia da colheita do arroz a gente faz mutirão. Por exemplo, se nós sairmos aqui e for viajar hoje, se nós chegarmos e falar pra um vizinho olhar aqui pra nós, é na hora. E já aconteceu e acontece". O assentado AX-14 confessa que "só raramente que nós ajudamos o outro; quando precisa mesmo, em último caso mesmo. Por exemplo quando um companheiro adoece ou viaja, aí nós ajudamos, quando pode também”.

Por meio dos depoimentos dos assentados, foi possível concluir que a reciprocidade, a mutualidade e a cooperação subjetiva, mesmo em momentos específicos, tecem as relações sociais e estruturam a organização social e produtiva no interior do assentamento. Isto é, mesmo que de forma espontânea, sem saber que praticam e criam redes de sociabilidades, os assentados afirmam que esse sentido subjetivo, de apoio mútuo, especialmente no que se refere ao processo de trabalho e produção, é um componente indispensável à manutenção e permanência no assentamento. Como bem observou Scopinho (2014, p. 183), as redes de sociabilidades que emergem no espaço rural são induzidas por razões "onde as necessidades são muitas e os recursos escassos, em que a manutenção das boas relações é importante para garantir a sobrevivência imediata".

Percebe-se que, no Assentamento São Bento, as redes de sociabilidades consolidam uma forma de convivência social assente no apoio mútuo conforme as necessidades surgem no cotidiano. Em grande parte, essas necessidades são provenientes de momentos específicos no processo de trabalho e produção, como é o caso do mutirão e da troca de dias, na urgência e em alguma eventualidade, como é o caso, por exemplo, de viagens e problemas de saúde.

O componente da mutualidade e da sensibilidade com a dificuldade do "outro" também está associado ao sentido da reciprocidade, o que é determinante para a elaboração das redes de sociabilidades. Significa que o apoio, numa eventual falta de condições de saúde para realizar as atividades básicas na parcela, se torna favorável para o retorno do favor prestado quando se fizer necessário. Trata-se, de certo modo, de retribuir o favor prestado em meio à momentânea dificuldade apresentada. Conforme depoimento do assentado AX-5, a condição de "trocar favores" é essencial para a manutenção das boas relações e convivência no interior do assentamento: 
caboco foi para Trindade, né, gosto demais da conta da avó dele, do avô dele que é falecido, porque eu era muito próximo deles, porque eu brincava com eles, era muito próximo mesmo. Nem tanto que esse vizinho nosso aqui precisou de mim várias vezes para levar ele para Goiânia, porque ele está doente. Muitas das vezes, também, eu precisei dos companheiros, e eles vieram. Às vezes a gente precisa e eles vêm. Mas assim... não são todos não. Porque é assim, eu ajudo um companheiro, o dia que eu precisar ele me ajuda, entende? É uma troca (ASSENTADO AX-5).

Observa-se que o auxílio mútuo, prestado em uma eventualidade, se torna condição para que futuramente o favor concedido seja devidamente retribuído. Essa é a lógica e a dinâmica da "troca de favores" no mundo rural, trata-se de uma "ética" e uma "moral" especificamente assentadas sobre os sujeitos sociais do campo, que acumulam favores como se fossem dívidas que, por uma questão de honra, devem ser "pagas" assim que possível. Em seu depoimento, o assentado AX-10 afirma que a troca de favores é uma forma de apoio mútuo que possibilita a todos continuarem sobrevivendo às dificuldades e percalços do dia a dia no campo:

de vez em quando nós ainda ajudamos o companheiro que precisa, sabe. As vezes está passando por dificuldade, aí a gente faz uma cesta e ajuda; ou então a gente até faz um dia de serviço pra ajudar nos afazeres, sabe. Então tem que ter essa troca, né, porque se não tiver essa troca com o companheiro, não tem como conseguir manter as coisas na roça...então tem que sempre manter essa troca de favor, né (ASSENTADO AX10).

A troca de favores é uma estratégia arraigada na cultura rural brasileira, onde o sujeito é constituído por uma rede de parentesco e agregações, o que facilita a aplicabilidade dessa estratégia. Martins $(2009$, p. 19) assevera que se trata de uma "teia básica de relações sociais imediatas dos assentados; uma série de relacionamentos que revigora uma sociabilidade primordialmente familística”. Segundo Quintero (2009) as ajudas do quotidiano entre vizinhos, amigos e familiares são corriqueiras, consistem nos favores, nas atenções para com os outros, ou seja, socorrem-se uns aos outros pontualmente, quando a ajuda é solicitada. Mas não é de todo descartado o auxílio programado entre familiares e compadres. De modo geral, as formas de apoio mútuo, de cooperação espontânea e de troca de favores, que acreditamos ser espaços em que se desenvolvem as redes de sociabilidades, somente resistem em razão dos vínculos e laços criados entre os assentados.

Em diversos sentidos, as redes de sociabilidades presentes no cotidiano dos assentados revelam que, em grande medida, o valor de troca, dimensionado pelo espectro econômico, tornam-se elementos secundários, enquanto as relações sociais alicerçadas na mutualidade, reciprocidade e cooperação espontânea dominam a vida cotidiana por meio da subjetividade. Opõem-se, assim, o valor de uso ao valor de troca. Em razão disso, “o valor de uso corresponde à necessidade, à expectativa, ao desejo imediato. $\mathrm{O}$ valor de troca 
corresponde à relação dessa coisa com as outras, com todos os objetos e com todas as coisas, no mundo da mercadoria" (LEFEBVRE, 2001, p. 135).

Não se trata apenas de produzir e comercializar, mas de haver um sentido, uma essência e uma referência subjetiva, simbólica e cultural, "pois é no instante dessas rupturas do cotidiano, nos instantes da inviabilidade da reprodução, que se instaura o momento da invenção, da ousadia, do atrevimento, da transgressão. E aí a desordem é outra, como é outra a criação" (MARTINS, 2008, p. 57). O valor de uso, ou seja, o sentido da obra, que não está por inteiro associado à mercadoria (valor de troca), pode ser verificado quando se questiona ao assentado o que a terra significa para si:

\section{eu acho que a terra representa a vida. Porque é dela que...como se diz...tudo acontece, né, tudo é quanto é forma que você pensar sai é da terra. A terra e a água são o bem mais precioso que todo mundo tem (ASSENTADO AX-3).}

Em muitos momentos da entrevista, especialmente quando perguntávamos sobre qual o sentido e a representatividade da terra para os assentados, eles demonstravam emoção. A terra representa, em primeiro lugar, a possibilidade de sobreviver do próprio esforço e trabalho, produzir para subsistência e comercializar os excedentes para aumentar a qualidade de vida da família. Em segundo, ter um pedaço de terra está associado à dignidade, à construção de laços e vínculos intrafamiliares e extrafamiliares, de reunião, do encontro, da festa, do lazer, da educação dos filhos, da tradição, dos costumes.

Desse modo, são as dimensões objetivas e subjetivas que constituem o cotidiano dos assentados que, em momentos específicos, é capturado pelo binômio capital-estado e rompido momentaneamente quando afloram o valor e o sentido do uso. Martins (2008, p. 56) observa que "mesmo na rotina alienadora da fábrica e da produção há momentos de iluminação e criação, de invasão do cotidiano e do senso comum pela realidade e pelo conhecimento que revolucionam o cotidiano".

A experiência do trabalho de campo junto aos assentados possibilitou compreender como o sentido do uso e do valor de uso em muitos períodos sobrepõem-se ao valor de troca. Desde o momento em que as entrevistas eram marcadas ou mesmo improvisadas, os assentados tiravam do seu tempo de trabalho e afazeres poucos minutos para narrar suas histórias e experiências. As visitas eram quase sempre regadas a uma conversa informal sobre os mais variados temas, a mencionar o clima, a política, o futebol. O orgulho e a satisfação dos assentados em mostrar e descrever a casa, a família, o veículo, a lavoura, o gado e o trabalho desenvolvido na parcela, foi um dos aspectos marcantes. Era como se quisessem dizer (e o diziam nos gestos e nas expressões) que tudo aquilo que conquistaram foi por meio de muito trabalho e esforço, e isso deveria ser evidenciado.

Desde o instante em que ocorrem a cooperação espontânea, o auxílio mútuo, a solidariedade e o compartilhamento de problemas e soluções entre os assentados, o significado e a representação do uso são retomados como possibilidade de ruptura do binômio capital-estado. E é exatamente neste ponto em que se revelam as redes de sociabilidades. Em certa medida, a formação de "redes" de sociabilidades são o resultado 
dos próprios vínculos de parentesco e vizinhança que se estruturam. E nos espaços rurais essa teia de relações aparece mais claramente, razão pela qual se justifica a solidariedade camponesa, uma característica desses ambientes (MARTINS, 2008).

Para Rosimeire Scopinho (2014), as redes de sociabilidades são meios pelos quais os indivíduos se relacionam naturalmente para escapar à objetividade da vida cotidiana. Seja na forma de vínculos parentais, amizades ou mesmo companheirismos diversos, as sociabilidades se arrolam no cotidiano por razões espontâneas, indiretas, nos interstícios da vida e das relações humanas. Na esteira dessa assertiva, Bergamasco (1994) analisa as redes de sociabilidades como estratégias de reprodução social dos sujeitos, como mecanismos de manutenção da vida e da sobrevivência. Essas estratégias são constantemente utilizadas no cotidiano, quando as formas e os meios institucionais, burocráticos e oficiais não são suficientes.

Ao contrário do que se possa imaginar, os assentamentos rurais são espaços complexos de relações sociais, não raro, caracterizados por dinamismos peculiares em que articulações e disputas estão constantemente sendo vivenciadas no cotidiano e que necessitam ser evidenciadas, tanto é que as redes de sociabilidades, responsáveis por agrupar os assentados das mais variadas formas, podem ser criadas e desmanchadas com grande velocidade, estabelecendo relações horizontais e verticais que ora incluem, ora segregam, ora aproximam e facilitam a criação de vínculos, ora afastam e geram tensões.

\section{Considerações finais}

Os processos organizativos do Assentamento São Bento em Heitoraí-GO constituem-se por meio de concepções e práticas sociais não apenas em relação ao modo de organizar o trabalho e a produção, mas, também, a outras dimensões da vida cotidiana, tais como a manutenção das boas relações e convívio social. Em tais circunstâncias, essas dimensões da vida cotidiana têm contribuído para que os assentados possam continuar a exercer suas atividades em suas parcelas mesmo em condições ainda distantes das ideais. Compreender a subjetividade como componente que integra o espaço social do assentamento é indispensável, pois revela outras possibilidades de reprodução social além das estabelecidas pela via do binômio capital-estado.

Com base no trabalho de campo desenvolvido no Assentamento São Bento, constatou-se que mesmo enviesados pelo cotidiano da produção, do trabalho, da comercialização, da negociação e da burocratização, há momentos em que os assentados desenvolvem formas de sociabilidades referenciadas pela reciprocidade, em auxílios mútuos e na cooperação que se arrola de forma espontânea e autônoma. Em grande medida, essas sociabilidades operam-se na qualidade de superação das condições precárias de trabalho e reprodução social, em formas de mutirões e troca de dias, igualmente no assistencialismo pessoal e de vizinhança. Esses modelos de sociabilidades criam redes que se integram em relações de proximidade geográfica dos lotes ou mesmo por intermédio de certa afetividade, de certa vizinhança e de certo parentesco. 
A experiência adquirida, na época do acampamento, em que o espaço geográfico, social e político era compartilhado, foi um atenuante fundamental para que as redes de sociabilidades se consolidassem no assentamento. Apesar de a união não ser a mesma à época do acampamento, os assentados ainda mantêm determinados vínculos e afetos que que se fazem valer no cotidiano. Tais vínculos contribuem para a convivência do grupo e auxiliam na reprodução social quando as condições materiais não são suficientes.

Todavia, cabe assinalar a necessidade de maior autonomia dos assentados no que se refere aos processos de organização do trabalho, produção e comercialização. Ainda assim, é preciso direcionar maior poder de decisão política e econômica aos assentados com o objetivo de fortalecer a permanência e a reprodução social desses sujeitos no espaço do assentamento, o que exigiria um esforço no sentido de desburocratizar as relações sociais e de trabalho. Cumpre também realçar a pertinência de estudos e pesquisas que possam contribuir com o tema dos assentamentos rurais a partir das dimensões da subjetividade e dos modos de vida. Em grande medida, deve-se procurar compreender não apenas o aspecto técnico, econômico e burocrático, mas, também, e, sobretudo, os processos sociais que envolvem as esferas da cooperação e das sociabilidades.

As possibilidades de pesquisa que se abrem a partir das discussões e reflexões acerca do associativismo e da cooperação, não apenas no âmbito dos assentamentos rurais, mas, também, em outros espaços sociais (cidade, casa, escolas, fábricas, ruas etc) são enormes e de grande potencial. Taís possibilidades implicam em considerar outras formas de organização e relações para além dos modelos e das forças hegemônicas do binômio capital-estado.

\section{Referências}

BERGAMASCO, S. M.; NORDER, L. C. O que são assentamentos rurais. São Paulo: Brasiliense, 1996. (Coleção Primeiros Passos).

BERGAMASCO, S. M. Assentamentos rurais: reorganização do espaço produtivo e processos de socialização. In: MEDEIROS, L. S.; ESTERCI, N. et al (Orgs).

Assentamentos rurais: uma visão multidisciplinar. São Paulo: Editora da Universidade Estadual Paulista, 1994.

BOURDIEU, P. Sociologia. Organizador [da coletânea] Renato Ortiz; tradução de Paula Monteiro e Alícia Auzmendi]. São Paulo: Ática, 1983.

CASTILHO, D. Tempo do espaço, tempo da vida: uma leitura socioespacial de Heitoraí. Goiânia: Editora e Gráfica Ellos, 2007.

CERTEAU, M. A invenção do cotidiano. $3^{\mathrm{a}}$ ed. Tradução de Ephraim Ferreira Alves. Petrópolis: Vozes, 1998.

CHRISTOFFOLI, P. I. Cooperação agrícola. In: CALDART, R. S. et al (Orgs.).

Dicionário da Educação do Campo. Rio de Janeiro, São Paulo: Escola Politécnica de

Saúde Joaquim Venâncio, Expressão Popular, 2012. 
FERRANTE, V. L. B. Diretrizes políticas dos mediadores: reflexões de pesquisas. In: MEDEIROS, L. S.; ESTERCI, N. et al (Orgs). Assentamentos rurais: uma visão multidisciplinar. São Paulo: Editora da Universidade Estadual Paulista, 1994.

GOIÁS. Instituto Mauro Borges de Estatística e Estudos Socioeconômicos. IMB. Perfil Socioeconômico dos Municípios Goianos: IMB, 2018. Disponível em:

http://www.imb.go.gov.br/perfil-dos-munic\%C3\%ADpios-goianos.html (acesso: 03 abr. 2020).

GONÇALVES, R. de C.; LISBOA, T. K. Sobre o método da história oral em sua modalidade trajetórias de vida. Kátalysis, Santa Catarina, vol. 10, p. 83-92, fev./mai. 2007. Disponível em: <https://periodicos.ufsc.br/index.php/katalysis/article/view/S141449802007000300009>.

IANNI, O. Origens Agrárias do Estado Brasileiro. São Paulo: brasiliense, 2004.

LEFEBVRE, H. Espaço e Política: o direito à cidade II. Tradução de Margarida Maria de Andrade, Pedro Henrique Denski e Sérgio Martins. 2. Ed. ver. e ampl. Belo Horizonte: Editora UFMG, 2016.

LEFEBVRE, H. A vida cotidiana no mundo moderno. Tradução: Alcides João de Barros. São Paulo: Ática, 1991.

LEFEBVRE, H. A cidade do capital. $2^{\mathrm{a}}$ ed. Tradução de Maria Helena Rauta Ramos e Marilena Jamur. Rio de Janeiro: DP\&A, 2001.

MARTINS, José de Souza. Os Camponeses e a Política no Brasil. $2^{\circ}$ ed. Petrópolis: Vozes 1983.

LEFEBVRE, H. A sociabilidade do homem simples: cotidiano e história na modernidade anômala. $2^{a}$ ed. revista e ampliada. São Paulo: Contexto, 2008.

LEFEBVRE, H. Travessias: a vivência da reforma agrária nos assentamentos. $2^{\mathrm{a}}$. ed. Porto Alegre: Editora da UFRGS, 2009.

QUINTERO, M. da C. Rio Paraíso, o paraíso conquistado. In: Travessias: a vivência da reforma agrária nos assentamentos. 2ª . ed. Porto Alegre: Editora da UFRGS, 2009.

SCOPINHO, R. A. Processos organizativos de assentamentos rurais: trabalho, condições de vida e subjetividades. São Paulo: Annablume, 2012.

SCOPINHO, R. A. Representações sociais sobre associativismo e agroecologia em assentamentos rurais de reforma agrária. In: MARTINS, Rodrigo Constante (Org.). Ruralidades, trabalho e meio ambiente: diálogos sobre sociabilidades rurais contemporâneas. São Carlos: Edufscar, 2014.

SEABRA, O. C. de L. A insurreição do uso. In: MARTINS, José de Souza (Org.) Henri Lefebvre e o retorno à dialética. São Paulo: Hucitec, 1996. 
ZIMMERMANN, N. de C. Os desafios da organização interna de um assentamento rural. In: MEDEIROS, L. S; ESTERCI, N. et al (Orgs). Assentamentos rurais: uma visão multidisciplinar. São Paulo: Editora da Universidade Estadual Paulista, 1994.

\section{Fontes Orais}

AX-1, Entrevista I. [mar. 2017]. Entrevistador: Jean Carlos Ribeiro de Lima. Heitoraí, 2017. 1 arquivo. $\mathrm{mp} 3$ (30 $\mathrm{min}$.).

AX-3, Entrevista III. [jun. 2017]. Entrevistador: Jean Carlos Ribeiro de Lima. Heitoraí, 2017. 1 arquivo. mp3 (42:56 min.).

AX-4, Entrevista IV. [jul. 2017]. Entrevistador: Jean Carlos Ribeiro de Lima. Heitoraí, 2017. 1 arquivo. $\mathrm{mp} 3$ (33 $\mathrm{min}$.).

AX-5, Entrevista V. [jul. 2017]. Entrevistador: Jean Carlos Ribeiro de Lima. Heitoraí, 2017. 1 arquivo. $\mathrm{mp} 3$ (24 min.).

AX-6, Entrevista VI. [jul. 2017]. Entrevistador: Jean Carlos Ribeiro de Lima. Heitoraí, 2017. 1 arquivo. mp3 (30:22 min.).

AX-7, Entrevista VIII. [jul. 2017]. Entrevistador: Jean Carlos Ribeiro de Lima. Heitoraí, 2017. 1 arquivo. $\mathrm{mp} 3$ (60 $\mathrm{min}$.).

AX-9, Entrevista VIII. [jul. 2017]. Entrevistador: Jean Carlos Ribeiro de Lima. Heitoraí, 2017. 1 arquivo. $\mathrm{mp} 3$ (58:25 $\mathrm{min}$.).

AX-10, Entrevista X. [jul. 2017]. Entrevistador: Jean Carlos Ribeiro de Lima. Heitoraí, 2017. 1 arquivo. mp3 (36:29 min.).

AX-14, Entrevista XV. [jul. 2017]. Entrevistador: Jean Carlos Ribeiro de Lima. Heitoraí, 2017. 1 arquivo. mp3 (37:25 min.).

AX-15, Entrevista XV. [jul. 2017]. Entrevistador: Jean Carlos Ribeiro de Lima. Heitoraí, 2017. 1 arquivo. $\mathrm{mp} 3$ (43:19 $\mathrm{min}$.).

Agradecimento: à Fundação de Amparo à Pesquisa do Estado de Goiás (FAPEG) pela concessão de bolsa de estudos, o que permitiu o desenvolvimento de pesquisa junto ao Programa de Mestrado em Territórios e Expressões Culturais do Cerrado (TECCER/UEG), sob orientação da Profa. Dra. Mary Anne Vieira Silva e defendida no ano de 2018.

\section{Jean Carlos Ribeiro de Lima}

Mestre em Ciências Sociais e Humanidades pela Universidade Estadual de Goiás.

Graduado em História pela Universidade Estadual de Goiás. Atualmente é professor

da rede privada e pública de ensino.

Av. Brasil, 181, 76300-000, Ceres, Goiás.

E-mail: jean_ribeiro_lima@hotmail.com

Recebido para publicação em outubro de 2019

Aprovado para publicação em dezembro de 2019 